\title{
Holoprosencephaly-caudal dysgenesis syndrome
}

INSERM

\section{Source}

INSERM. (1999). Orphanet: an online rare disease and orphan drug data base. Holoprosencephaly-caudal dysgenesis syndrome. ORPHA:2165

Holoprosencephaly-caudal dysgenesis syndrome is a central nervous system malformation syndrome characterized by holoprosencephaly with microcephaly, abnormal eye morphology (hypotelorism, cyclopia, exophthalmos), nasal anomalies (single nostril or absent nose), and cleft lip/palate, combined with signs of caudal regression (sacral agenesis, sirenomelia with absent external genitalia). 